ISSN (Print) : :1412-7601

ISSN (Online) : 2654-8712

Volume 6, No.1 Maret 2020

EKONOBIS

http://www.ekonobis.unram.ac.id

\title{
Tracer Studi Dan Relevansi Kurukulum Konsentrasi Hotel Dan Restoran Terhadap Pasar Tenaga Kerja Alumni D3 Pariwisata Fakultas Ekonomi Dan Bisnis Universitas Mataram
}

\author{
Hadi Mahmudi, Satarudin, Muhamad Alwi.
}

Universitas Mataram ARTICLE INFO

Keywords :

Curriculum, Hotel and

Restaurant, Labor Market

Kata Kunci :

Kurikulum, Hotel dan

Restoran, Pasar Tenaga

Kerja.
ABSTRACT : This study aims to: determine the suitability of the curriculum in the concentration of Hotels and Restaurants Tourism D3 Study Program to the needs of expertise in the labor market in tourism and find out whether the subject of the Hotel D3 Hotel and Restaurant concentration needs to be adjusted to the needs of expertise in the labor market in the field tourism. The analysis technique used is descriptive analysis with a quantitative approach. The output that will be produced in this study is the relevance of the curriculum to the needs of the labor market which will increase the demand for alumni concentration of hotels and restaurants D3 FEB Unram tourism. The results of the study provide an overview of alumni user responses and the relevance of the curriculum in the D III Program of Tourism Concentration at the Hotel and Restaurant Faculty of Economics and Business, University of Mataram in accordance with the course groups are as follows: The students who did the Job Training (PKL) said the relevance of the curriculum based on the group of subjects to the labor market, namely: the Scientific and Expertise Subjects Group (MKK) had sufficient relevance to the needs of the labor market. lack of relevance to the needs of the labor market, the Group of work behavior subjects (MPB) has less relevance to the needs of the labor market, the community livelihoods group ( $M B B$ ) has less relevance to the needs of the labor market. Based on the results of the discussion the following solutions can be given: In connection with expertise based on the field of science or main competencies, curriculum reconstruction and improvement in the quality of teaching and learning processes, especially laboratory facilities and infrastructure, are completed. Regarding expertise based on integrity, communication and teamwork of students needs to be improved soft skills by the way students are encouraged to take part in extracurricular activities that are of interest.

ABSTRAK: Penelitian ini bertujuan untuk: mengetahui kesesuaian kurikulum pada
konsetrasi Hotel dan Restaurant Program Studi D3 Pariwisata terhadap kebutuhan keahlian pada pasar tenaga kerja di bidang pariwisata dan mengetahui mata kuliah apakah pada Konsentrasi Hotel dan Restaurant D3 pariwisata diperlukan penyesuaian dengan kebutuhan keahlian pada pasar tenaga kerja di bidang pariwisata. Tekhnik analisis yang digunakan adalah analisis deskriftif dengan pendekatan kuantitatif. Output yang akan dihasilkan dalam penelitian ini adalah adanya relevansi kurikulum dengan kebutuhan akan pasar tenaga kerja yang akan meningkatkan permintaan tenaga kerja alumni konsentrasi Hotel dan Restoran D3 pariwisata FEB Unram.

Hasil penelitian memberikan gambaran tentang tanggapan pengguna alumni dan relevansi kurikulum Program D III Pariwisata Konsentrasi Hotel dan Restoran Fakultas Ekonomi dan Bisnis Universitas Mataram sesuai dengan kelompok matakuliah adalah sebagai berikut: Pihak pengguna mengatakan bahwa kemampuan alumni secara umum masih dibawah standar rata-rata kompetensinya. Pihak mahasiswa yang melakukan Praktek Kerja Lapangan (PKL) mengatakan relevansi kurikulum berdasarkan kelompok matakuliah terhadap pasar tenaga kerja yaitu: Kelompok Mata Kuliah Keilmuan dan Keahlian (MKK) mempunya relevansi yang cukup terhadap kebutuhan pasar tenaga kerja, Kelompok mata kuliah keahlian berkarya (MKB) mempunyai relevansi kurang terhadap kebutuhan pasar tenaga kerja, Kelompok matakuliah perilaku berkarya (MPB) mempunyai relevansi kurang terhadap kebutuhan pasar 


\begin{tabular}{l|l}
\hline & tenaga kerja, Kelompok matakuliah berkehidupan bermasyarakat (MBB) mempunyai \\
& relevansi kurang terhadap kebutuhan pasar tenaga kerja. Berdasarkan hasil \\
pembahasan dapat diberikan solusi sebagai berikut: Berkaitan dengan keahlian \\
berdasarkan bidang ilmu atau kompetensi utama dilakukan rekontruksi kurikulum dan \\
peningkatan kualitas proses belajar mengajar, terutama sarana dan prasarana \\
laboratoriumnya dilengkaapi. Berkaitan dengan keahlian berdasarkan integritas, \\
komunikasi dan kerjasama tim mahasiswa perlu ditingkatkan soft skillnya dengan cara \\
mahasiswa didorong untuk mengikuti kegiatan exktra kurikuler yang diminati.
\end{tabular}

2020, EKONOBIS All right reserved 


\section{PENDAHULUAN}

\section{Latar Belakang}

Dinamika Industri pariwisata Indonesia menunjukkan pergerkan yang sangat dinamis. Hal ini terkait erat karena industri pariwisata Indonesia sangat sensitif terhadap isu keamanan. terorisme dan kesehatan. Berbagai isu keamanan seperti Bali Bombing, perang teluk dan isu keamanan regional. serta isu kesehatan seperti SARS. Flu burung ikut mempengaruhi dinamika industri pariwisata Indonesia. Indonesia khususnya Nusa Tenggara Barat (NTB) yang telah di tunjuk oleh pemerintah melalui design master plan sebagai koridor pariwisata telah berhasil melewati berbagai tantangan dan hambatan dalam tingkat global maupun nasional dan domestik.

Perkembangan industri pariwisata yang sangat dinamis juga dipengaruhi banyak faktor seperti sumber daya manusia yang dimiliki di suatu wilayah. Perkembangan industri pariwisata di wilayah NTB tidak dapat dipisahkan dengan kesiapan sumber daya manusia dibidang pariwisata. Oleh karena itu sumber daya manusia pariwisata merupakan aspek kunci dalam pengembangan wisata di NTB.
Universitas Mataram merupakan salah satu lembaga pendidikan negeri dan terbesar di Provinsi NTB. Salah satu tanggung jawab terbesar Universita Mataram adalah menyiapkan sumber daya pariwisata yang terampil dan terdidik untuk dapat berkontibusi pada sector pariwisata di NTB. Tanggung jawab tersebut telah dipikul oleh Universitas Mataram dengan memiliki Program Studi Diploma 3 (tiga) Pariwisata untuk dapat menyiapkan tenaga kerja terdidik. terlatih agar siap terjun langsung dalam dunia periwisata di NTB. Untuk mendukung hal tersebut. Program Studi Diploma 3 (tiga) Pariwisata memiliki staff tenaga pengajar yang telah terbukti profesional dan ahli dalam bidangnya baik dari kalangan professional (dosen) dan praktis (tenga professional dalam industri pariwisata).

$$
\text { Ketersediaan sumber daya }
$$

manusia yang berkualitas dalam membentuk insani pariwisata di NTB juga didukung oleh infastruktur design pembelajaran yang diberikan. Sesuai dengan acuan Standar Nasional bahwa Diploma 3 (tiga) Pariwisata berada pada standar 5 dengan kebutuhan $60 \%$ mata kuliah adalah kuliah praktikum dan $40 \%$ mata kuliah teori. Acuan standar ini yang 
kemudian di breakdown untuk memenuhi kebutuhan industri sector pariwisata. Sehingga penelitian tentang "Analisis kesesuaian kurikulum dengan kebutuhan dunia kerja Pada Alumni konsentrasi Hotel dan Restaurant Program Studi Diploma 3 Pariwisata Hotel dan Restaurant" sangat penting untuk dilakukan untuk mempersiapkan sumber daya pariwisata yang lebih baik.

\section{Identifikasi Masalah}

1. Keberadaan dan karir pekerjaan yang dilakukan oleh alumni sering tidak relevan dangan mata kuliah yang ditawarkan oleh Program Studi Diploma 3 Pariwisata.

2. Terdapat permasalahan kesesuaian antara relevansi kurikulum dengan kemampuan yang dibutuhkan di dunia kerja.

3. Kompetensi yang dibutuhkan dalam dunia kerja terkadang tidak sesuai dengan ilmu yang didapat.

\section{Batasan Masalah}

Penelitian ini hanya membatasi masalah pada relevansi kurikulum (mata kuliah) dengan tuntutan keahlian lulusan dalam bidang pekerjaan di masyarakat dan kompetensi yang dibutuhkan dalam dunia kerja.

\section{Rumusan Masalah}

1. Bagaimana kesesuaian kurikulum pada konsetrasi Hotel dan Restaurant Program Studi D3 Pariwisata terhadap kebutuhan keahlian pada pasar tenaga kerja di bidang pariwisata?

2. Mata kuliah apakah pada Konsentrasi Hotel dan Restaurant D3 pariwisata diperlukan penyesuaian dengan kebutuhan keahlian pada pasar tenaga kerja di bidang pariwisata?

\section{Tujuan Penelitian}

1. Untuk mengetahui kesesuaian kurikulum pada konsetrasi Hotel dan Restaurant Program Studi D3 Pariwisata terhadap kebutuhan keahlian pada pasar tenaga kerja di bidang pariwisata?

2. Untuk mengetahui mata kuliah apakah pada Konsentrasi Hotel dan Restaurant D3 pariwisata diperlukan penyesuaian dengan kebutuhan keahlian pada pasar tenaga kerja di bidang pariwisata?

\section{Manfaat penelitian}

Penelitian ini diharapkan memberikan manfaat untuk mendapatkan umpan balik tentang sistem atau proses pembelajaran terutama kurikulum (mata kuliah) yang ditawarkan pada Program Studi D3 Pariwisata dengan tuntutan di dunia kerja. 


\section{TINJAUAN PUSTAKA}

\section{Pengertian Kurikulum}

Kurikulum adalah rencana tertulis tentang kemampuan yang harus dimiliki berdsarakan standar nasional, materi yang perlu dipelajari dan pengalaman belajar yang harus dijalani oleh peserta didik untuk mencapai kemampuan yang telah direncanakan, dan relevansi yang perlu dilakukan untuk menentukan tingkat pencapaian kemampuan peserta didik serta seperangkat peraturan yang berkena dengan pengalaman belajar peserta didik dalam mengembangkan potensi dirinya pada satuan pendidikan tertentu (Hamalik 2008;91).

Suatu kurikulum disusun untuk mewujudkan tujuan pendidikan nasioanl dengan memperhatikan tahap perkembangan peserta didik dan kesesuaian denag lingkungan, kebutuhan pembangunan nasional, perkembangan ilmu pengetahuan dan teknologi serta kesenian, sesuai dengan jenis dan jenjang masing-masing satuan pendidikan (Hamalik. 2008;92).

\section{Fungsi Kurikulum}

Menurut Hmalik fungsi kurikulum adalah sebagai berikut (Hmalik.20018):

a. Fungsi Integrasi, kurikulum sebagai alat pendidikan harus mampu menghasilkan pribadi-pribadi yang utuh. Peserta didik pada dasarnya merupakan anggota dan bagian intergral masayarakat ke jenjang yang lebih tinggi.

b. Fungsi Penyesuaian, kurikulum sebagai alat pendidikan harus mampu mengarahkan peserta didik memiliki sifat well adjust. yaitu mampu menyesuaikan dirinya dengan lingkuan. baik lingkungan fisik maupun lingkungan social.

c. Fungsi Diferensiasi, kurikulum sebagai alat pendidikan harus mampu memberikan layanan terhadap perbedaan individu peserta didik. Setiap peserta didik memliki perbedaan baik dari aspek fisik maupun psikis.

d. Fungsi Diagnostik, kurikulum sebagai alat pendidikan harus mampu membantu dan dan mengarahkn peserta didik untuk dapat memahami dan menerima potensi dan kelemahan-kelemahan yang ada pada dirinya masingmasing.

e. Fungsi Pemilihan, kurikulum sebagai alat pendidikan harus mampu mempersiapkan peserta didiknya melanjutkan studi ke 
jenjang pendidikan yang lebih tinggi.

f. Fungsi Persiapan, kurikulum sebagai alat pendidikan harus mampu mempersiapkan peserta didiknya melanjutkan studi ke jenjang pendidikan yang lebih tinggi.

\section{Model-Model Kurikulum}

a. Model Kurikulum subjek akademik, kurikulum ini menekankan pada isi atau materi berkaitan dengan ilmu pengetahuan yang diambil dari dari disiplin-disiplin ilmu.

b. Model Kurikulum teknologis, kurikulum ini menekankan pada isi kurikulum tetapi isinya bukan diambil atau menunjukkan disiplin ilmu tetapi berupa kompetensi atau kecakapan dan keterampilan.

c. Model Kurikulum humanitis, model kurikulum ini menekankan pada pengembangan kepribadian secara utuh dan seimbang antara perkembangan segi intelektual, efektif dengan psikomotor.

d. Model Kurikulum rekonstruksi social, model kurikulum ini menekankan pemecahan permasalahanpermasalahan yang secara nyata dihadapi masayarakat yang menekankan pembelajaran kooperatif dalam berbagai kegiatan kelompok.(Tim Pengembangan ilmu pendidikan UPL.2007)

\section{Kebutuhan Dunia Kerja}

Memasuki abad ke 21 yang ditandai oleh liberlisme perdagangan diperlukan upaya sungguh sungguh untuk meningkatkan kualitas sumber daya manusia (SDM) yang benar-benar siap menghadapi poersaingan global yang makin terbuka. Permasalahan yang dihadapi lulusan PTN maupun PTS (SDM) di indonesia adalah ketidaksiapan saat akan memasuki dunia kerja. Hal ini menjadi tantangan bagi dunia pendidikan di Indonesia agar mampu menciptakan tenaga kerja yang professioanal sehingga SDM Nega Indonesia mampu bersaing dengan SDM negara lain sepertin Malaysia, Singapura, dan Filipina. Oleh karena itu, tumtutan untuk berani melakukan inovasi dan bekerja sungguh-sunggu untuk mempersiapkan sumber daya manusia masa depan yang sudah terdidik untuk bersaing dalam dunia kerja harus ditindaklanjuti. SDM yang diinginkan di era globalisasi ini tidak hanya bsebagai pekerja. tetapi juga sebagai wirausahawan (entrepreneurs), sejalan dengan kebijakan pemerintah dalam hal ini departemen pendidikan nasional, maka proses pendidikan diperguruan tinggi harus 
memperhatikan lingkungan dan tuntunan kebutuhan dunia kerja, khususnya dunia usaha dan dunia industry, terhadap SDM yang profesional.

Dunia kerja pada masa mendatang akan menjaring secara selektif calon tenaga kerja yang benar-benar profesional pada bidangnya, oleh karena itu salah satu tantangan utama bagi lulusan perguruan tinggi adalah mempersiapkan diri sebaik-baiknya sebelum memasuki dunia kerja, upaya peningkatan SDM khususnya dalam pendidikan tinggi adalah melalui program Co-Op ( Co-Operative Education). RAPID ( Riset Andalan Perguruan Tinggi dan Industri) dan program riset unggulan lainnya yang merupakan sarana penting bagi pengembangan diri dan kemampuan berwirausaha serta kemandirian secara profesional bagi lulusannnya untuk menghadapi tuntutan tersebut. Direktur Jenderal Pendidikan Tinggi untuk Pelita VI dan menyongsong tonggak-tonggak waktu tahun 2005 dan 2020 adalah ; "Penataan Sistem Pendidikan Tinggi agar lebih sesuai dengan kebutuhan Masyarakat dan Pembangunan".

\section{Road Map Peneltian}

Peta jalan penelitian dalam melakukan penelitian ini adalah sebagai berikut : Sasaran akhir dari kegitan penelitian tracer studi adalah tercapainya kesesuaian kurikulum konsentrasi perhotelan dan restoran pada Prodi D3 Pariwisata Fakultas Ekonomi dan Bisnis (FEB) UNRAM terhadap keahlian yang dibutuhkan oleh pasar tenaga kerja di bidang perhotelan dan restoran. Pada tahap awal, dilakukan identifikasi kurikulum yang dipakai saat ini kemudian diadakan focus group discussion (FGD) dengn pihak pengguna alumni Prodi D3 Pariwisata FEB UNRAM konsentrasi hotel dan restoran. Berdasarkan hasil FGD tersebut dapat diambil sebagai bahan pertimbangan untuk melakukan perubahan kurikulum atau tidak. 


\section{Bagan 2.1. Road Map Penelitian}

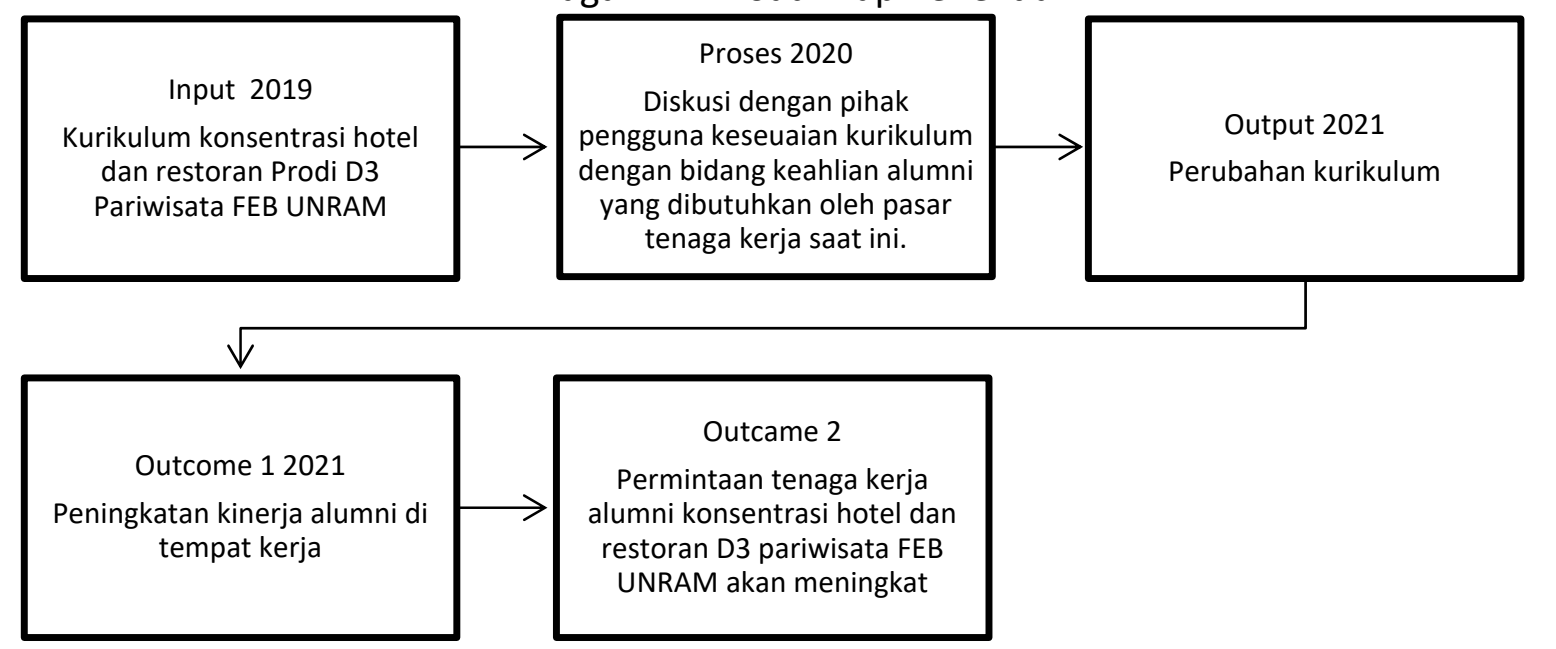

Selanjutnya dengan adanya perubahan kurikulum diharapkan dapat miningkatkan kinerja alumni dan apabila kurikulum tidak ada perubahan perlu ditingkatkan pendalamannya. Pada akhirnya permintaan pasar tenaga kerja terhadap alumni D3 pariwisata khusunya konsentrasi perhotelan dan restoran akan meningkat. Hal ini akan mendorong minat tamatan SLA untuk masuk kuliah di D3 pariwisata FEB UNRAM.

\section{METODE PENELITIAN}

\section{Jenis Penelitian}

Jenis penelitian yang digunakan dalam penelitian ini adalah penelitian deskriptif evaluatif yaitu penelitian yang berusaha mendeskripsikan profil lulusan dan relevansi kurikulum (materi kuliah) program studi pariwisata melalui pendekatan survei Penentuan lokasi penelitian dilakukan secara purposive sampling yaitu menentukan lokasi penelitian secara sengaja, lokasi penelitian adalah di pulau Lombok.

\section{Jenis dan Sumber Data}

\section{Jenis Data}

Jenis data dalam penelitian ini adalah:

a. Data kuantitatif yaitu data yang diperlukan dalam penelitian berupa angkaangka yang dapat diukur besarnya dan dapat dihitung secara pasti seperti data jumlah alumni program studi ekonomi pembangunan fakultas ekonomi universitas mataram selama 5 tahun terakhir dari tahun 2012-2017

b. Data kualitatif yaitu data yang diperlukan dwwenelitian ini berupa keterangan dan kebijakan yang berkaitan dengan pengembangan program studi 
diploma 3 pariwisata fakultas ekonomi universitas mataram

\section{Sumber data}

Data primer adalah data yang diperoleh secara langsung dari alumni yang dapat memberikan informasi atau keterangan yang diperlukan untuk kebutuhan penelitian. Data primer diperoleh dari kuesioner/daftar pertanyaan yang dibagikan kepada alumni program studi pariwisata.

\section{Teknik dan alat pengumpul data}

Teknik yang digunakan dalam mengumpulkan data dalam penelitian ini adalah sebagai berikut:

1. Dokumentasi, yaitu pengumpulan data berupa catatan-catatan yang tersedia pada program studi diploma 3 pariwisata.

2. Wawancara, yaitu teknik pengumpulan data dengan cara tanya jawab langsung dengan responden dengan menggunakan kuesioner/angket yang dibagikan kepada alumni program studi pariwisata.

\section{Variabel Penelitian}

1. Jumlah lulusan Program Studi D III Pariwisata periode 2013-2017

2. Tanggapan pengguna terhadap kompetensi alumni
3. Mata kuliah pengembangan kepribadian (MPK)

4. Mata kuliah keahlian berkarya (MKB)

5. Mata kuliah perilaku berkarya (MPB)

6. Mata kuliah berkehidupan bermasyarakat (MBB)

\section{Metode Pengumpulan Data}

Metode pengumpulan data yang digunakan dalam penelitian ini adalah Metode pengambilan sampel yang digunakan dalam penelitian ini adalah nonprobability sampling dimana pengambilan sampel didasarkan pada pertimbangan subjek peneliti yaitu karena pertimbangan biaya, lokasi, waktu dan informasi yang dibutuhkan oleh peneliti. Metode nonprobabilily sampling yang digunakan adalah teknik accidental sampling, teknik penentuan sampel berdasarkan kebetulan, yaitu siapa yang kebetulan bertemu dengan peneliti dapat dijadikan sampel jika dipandang sesuai. Total sampel yang digunakan dalam penelitian ini adalah 28 orang responden (alumni) dan 10 pengguna.

\section{Teknik Analisis Data}

Teknik analisis data yang digunakan adalah analisis deskriptif dengan pendekatan kuantitatif untuk melihat gambaran dari lulusan (alumni) Program 
Studi D III Pariwisata Konsentrasi Hotel dan Restoran Fakultas Ekonomi dan Bisnis Universitas Mataram.

\section{HASIL DAN PEMBAHASAN}

Jumlah Lulusan Program Studi D III Pariwisata Fakultas Ekonomi Universitas Mataram. Program Studi D III Pariwisata
Fakultas Ekonomi Universitas Mataram selama periode tahun 2013/20142017/2018 sudah meluluskan dengan jumlah lulusan sebanyak 550 orang dengan Indek Prestasi Rata-rata 3,22. Untuk lebih jelasnya dapat dilihat pada table 4.1.

Tabel 4.1. Persentase Lulusan Reguler dengan IPK Tahun 2013/2018

\begin{tabular}{|c|c|c|c|c|c|c|c|c|}
\hline \multirow[b]{2}{*}{$\begin{array}{l}\text { Tahun } \\
\text { Akademik }\end{array}$} & \multicolumn{2}{|c|}{ Jumlah Lulusan } & \multicolumn{3}{|c|}{ IPK Lulusan Reguler } & \multicolumn{3}{|c|}{$\begin{array}{c}\text { Persentase Lulusan Reguler } \\
\text { dengan IPK : }\end{array}$} \\
\hline & $\begin{array}{c}\text { Reguler } \\
\text { bukan } \\
\text { Transfer }\end{array}$ & Transfer ${ }^{(2)}$ & Min & Rata2 & Mak & $<2,75$ & $2,75-3,50$ & $>3,50$ \\
\hline (1) & (2) & (3) & (4) & (5) & (6) & (7) & (8) & (9) \\
\hline $2013 / 2014$ & 65 & - & 2,53 & 3,14 & 3,56 & 6,15 & 83,08 & 10,77 \\
\hline $2014 / 2015$ & 122 & - & 2,67 & 3,16 & 3,81 & 2,46 & 81,97 & 15,57 \\
\hline $2015 / 2016$ & 138 & - & 2,64 & 3,12 & 3,93 & 1,45 & 81,6 & 17,39 \\
\hline $2016 / 2017$ & 112 & - & 2,92 & 3,32 & 3,96 & 6,85 & 63,01 & 30,14 \\
\hline $2017 / 2018$ & 113 & - & 2,83 & 3,34 & 3,77 & - & 81,68 & 28,32 \\
\hline Jumlah & 550 & - & & & 3,22 & & & \\
\hline
\end{tabular}

Sumber : Bagian Kemahasiswaan FEB Unram dan SK. Yudisium

4.2. Hasil studi pelacakan Tanggapan Pihak Pengguna Lulusan.

Alumni Program Studi D III

Pariwisata Fakultas Ekonomi Universitas

Mataram sudah banyak bekerja di bidang perhotelan dan restoran khususnya alumni konsentrasi hotel dan restoran. Berdasarkan table 4.2. dapat dijelaskan bahwa dari tanggapan pihak pengguna sebanyak 10 orang terhadap Iulusan Program Studi D III Pariwisata Fakultas Ekonomi Universitas Mataram memberikan tanggapan baik terhadap kinerja alumni tertinggi di bidang komunikasi sebesar 68,75\%. Namun jika dilihat dari jenis kemampuan yang diberikan tanggapan sangat baik tertinggi hanya sebesar 43,75\%, yaitu pada kemampuan kerjasama tim. Artinya secara umum bahwa alumni Program Studi D III Pariwisata Fakultas Ekonomi Universitas Mataram masih banyak hal yang harus ditingkatkan kemampuan dan kualitas diri untuk lebih bisa bersaing dengan para alumni dari perguruan tinggi lain yang sejenis. Terutama pada kemampuan bahasa inggris karena penilaian yang diberikan oleh para pengguna dengan kreteria sangat baik pada posisi terendah yaitu sebesar 
12,50\%. Bagi pengelola Program Studi D III

Pariwisata Fakultas Ekonomi Universitas

Mataram perlu meningkatkan lagi dari inggris dengan cara memberikan sks prakteknya lebih banyak yang sesuai dengan profesinya.

segi kemampuan alumni terutama bahasa

Tabel 4.2. Hasil studi pelacakan Tanggapan Pihak Pengguna Lulusan

\begin{tabular}{|c|c|c|c|c|c|c|}
\hline \multirow[t]{3}{*}{ No. } & \multirow[t]{3}{*}{ Jenis Kemampuan } & \multicolumn{4}{|c|}{ Tanggapan Pihak Pengguna } & \multirow{3}{*}{$\begin{array}{c}\text { Rencana Tindak Lanjut } \\
\text { oleh Program Studi }\end{array}$} \\
\hline & & \multirow{2}{*}{$\begin{array}{c}\begin{array}{c}\text { Sangat } \\
\text { Baik }\end{array} \\
(\%)\end{array}$} & \multirow{2}{*}{$\begin{array}{l}\text { Baik } \\
\%) \\
\end{array}$} & \multirow{2}{*}{$\begin{array}{c}\text { Cukup } \\
(\%) \\
\end{array}$} & \multirow{2}{*}{$\begin{array}{c}\text { Kuran } \\
\mathrm{g} \\
(\%) \\
\end{array}$} & \\
\hline & & & & & & \\
\hline (1) & (2) & (3) & (4) & (5) & (6) & (7) \\
\hline 1 & $\begin{array}{l}\text { Integritas (etika dan } \\
\text { moral) }\end{array}$ & 37,50 & 56,25 & 6,25 & - & $\begin{array}{l}\text { Peningkatkan soft skill } \\
\text { mahasiswa }\end{array}$ \\
\hline 2 & $\begin{array}{l}\text { Keahlian berdasarkan } \\
\text { bidang ilmu } \\
\text { (kompetensi utama) }\end{array}$ & 18,75 & 62,50 & 12,50 & - & $\begin{array}{l}\text { Rekonstruksi kurikulum } \\
\text { dan pening katan } \\
\text { kualitas PBM }\end{array}$ \\
\hline 3 & Bahasa Inggris & 12,50 & 62,50 & 25,00 & - & $\begin{array}{l}\text { Meningkatkan kualitas } \\
\text { PBM bahasa Inggris }\end{array}$ \\
\hline 4 & $\begin{array}{l}\text { Penggunaan teknologi } \\
\text { informasi }\end{array}$ & 37,50 & 62,50 & - & - & $\begin{array}{l}\text { Peningkatkan kualitas } \\
\text { PBM bidang teknologi } \\
\text { informasi }\end{array}$ \\
\hline 5 & Komunikasi & 31,25 & 68,75 & - & - & $\begin{array}{l}\text { Peningkatkan soft skill } \\
\text { mahasiswa }\end{array}$ \\
\hline 6 & Kerjasama tim & 43,75 & 50,00 & 6,25 & - & $\begin{array}{l}\text { Peningkatkan soft skill } \\
\text { mahasiswa }\end{array}$ \\
\hline 7 & Pengembangan diri & 37,50 & 56,25 & 6,25 & - & $\begin{array}{l}\text { Peningkatkan soft skill } \\
\text { mahasiswa }\end{array}$ \\
\hline & Total & 218,75 & 418,75 & 62,5 & - & \\
\hline & Rata-rata & 31,25 & 59,47 & & & \\
\hline
\end{tabular}

Sumber : Tracer Studi tahun 2017/2018

\subsection{Relevansi Kurikulum D III Pariwisata}

\section{Konsentrasi Perhotelan dengan Pasar}

\section{Tenaga Kerja}

Kepmendiknas RI Nomor 232/U/2000

Tentang Pedoman Penyusunan Kurikulum

Pendidikan Tinggi Dan Penilaian Hasil

Belajar Mahasiswa. Kurikulum pendidikan

tinggi yang menjadi dasar

penyelenggaraan program studi terdiri atas:

a. Kurikulum inti; b. Kurikulum institusional.

Kurikulum inti merupakan kelompok bahan kajian dan pelajaran yang harus dicakup dalam suatu program studi yang dirumuskan dalam kurikulum yang berlaku secara nasional.

Kurikulum inti terdiri atas kelompok rnatakuliah pengembangan kepribadian, kelompok mata kuliah yang mencirikan tujuan pendidikan dalam bentuk penciri ilmu pengetahuan dan 
ketrampilan, keahlian berkarya, sikap berperilaku dalam berkarya dan cara berkehidupan bermasyarakat, sebagai persyaratan minimal yang harus dicapai peserta didik dalam penyelesaian suatu program studi. Kurikulum inti program diploma sekurang-kurangnya $40 \%$ dari jumlah SKS kurikulum program diploma. Kurikulum inti untuk setiap program studi pada program sarjana, program magister, program doktor, dan program diploma ditetapkan oleh Menteri. Sedangkan kurikulum institusional untuk setiap program studi pada program sarjana, program magister, program doktor, dan program diploma ditetapkan oleh masingmasing perguruan tinggi.

Kurikulum institusional merupakan sejumlah bahan kajian dan pelajaran yang merupakan bagian dari kurikulum pendidikan tinggi, terdiri atas tambahan dan kelompok ilmu dalam kurikulum inti yang disusun dengan memperhatikan keadaan dan kebutuhan lingkungan serta ciri khas perguruan tinggi yang bersangkutan.

Kurikulum institusional program sarjana dan program diploma terdiri atas keseluruhan atau sebagian adalah sebagai berikut:

1. Kelompok MPK yang terdiri atas matakuliah yang relevan dengan tujuan pengayaan wawasan, pendalaman intensitas pemahaman dan penghayatan MPK inti;

2. Kelompok MKK yang terdiri atas mata kuliah yang relevan untuk memperkuat penguasaan dan memperluas wawasan kompetensi keilmuan atas dasar keunggulan kompetitif serta komparatif penyelenggaraan program studi bersangkutan;

3. Kelompok MKB yang terdiri atas matakuliah yang relevan, bertujuan untuk memperkuat penguasaan dan memperluas wawasan kompetensi keahlian dalam berkarya di masvarakat sesuai dengan keunggulan kompetitif serta komparatif penyelenggaraan program studi bersangkutan;

4. Kelompok MPB yang terdiri atas matakuliah yang relevan, bertujuan untuk memperkuat penguasaan dan memperluas wawasan perilaku berkarya sesuai dengan ketentuan yang berlaku di masyarakat untuk setiap program studi;

5. Kelompok MBB yang terdiri atas matakuliah yang relevan dengan upaya pemahaman serta penguasaan ketentuan yang berlaku dalam berkehidupan di masyarakat, baik 
secara nasional maupun global, yang membatasi tindak kekaryaan seseorang sesuai dengan kompetensi keahliannya.

Kurikulum inti dan insitusional Program Diploma III Pariwisata Konsentrasi Hotel dan Restoran Fakultas Ekonom iUniversitas Mataram dialokasikan pada kelompok-kelompok mata kuliah sebagai berikut::

\subsubsection{Kelompok Mata Muliah}

\section{Pengembangan Kepribadian (MPK)}

Kelompok matakuliah pengembangan kepribadian (MPK) adalah kelompok bahankajian dan pelajaran untuk mengembangkan manusia Indonesia yang beriman danbertaqwa terhadap Tuhan Yang Maha Esa dan berbudi pekerti luhur, berkepribadian mantap, dan mandiri serta mempunyai rasa tanggung jawab kemasyarakatan dan kebangsaan.

Kelompok MPK pada kurikulum inti yang wajib diberikan dalam kurikulum setiap program studi/kelompok program studi terdiri atas Pendidikan Pancasila, Pendidikan Agama dan Pendidikan Kewarganegaraan. Sedangkan kelompok MPK secara institusional dapat termasuk bahasa Indonesia, bahasa Inggris, Ilmu Budaya Dasar, IImu Sosial Dasar, IImu Alamiah Dasar, Filsafat Ilmu, Olah Raga dan sebagainya.

Program D III Pariwisata Konsentrasi Hotel dan Restoran Fakultas Ekonomidan Bisnis Universitas Mataram dalam kelompok Mata Kuliah Pengembangan Kepribadian (MPK) adalah sebagai berikut:

Tabel 4.3. Mata Kuliah Pengembangan Kepribadian (MPK)

\begin{tabular}{|c|c|c|c|c|}
\hline \multirow{2}{*}{ No. } & \multirow{2}{*}{$\begin{array}{l}\text { Mata Kuliah Pengembangan Kepribadian } \\
\text { (MPK) }\end{array}$} & \multicolumn{2}{|c|}{ SKS } & \multirow{2}{*}{ Kurikulum } \\
\hline & & $\mathbf{w}$ & $\mathbf{P}$ & \\
\hline 1. & Pendidikan Kewarganegaraan & 2 & & Inti \\
\hline 2. & Pancasila & 2 & & Inti \\
\hline 3. & Pendidikan Agama & 2 & & Inti \\
\hline 4. & Bahasa Indonesia & & 2 & Institusional \\
\hline & Total & 6 & 2 & \\
\hline
\end{tabular}

Sumber: Buku Pedoman Akademik D III Pariwisata FEB Unram

Kelompok Mata Kuliah

Pengembangan Kepribadian (MPK) idalam penelitian ini tidak termasuk kelompok mata kuliah yang tidak diikutkan dalam analisa relevansi kurikulum dengan pasar tenaga kerja, karena kelompok MPK merupakan mata kuliah wajib nasional yang harus diberikan dalam kurikulum setiap program studi/kelompok program studi.

Materi mata kuliah MPK untuk Program D III Pariwisata Konsentrasi Hotel dan 
Restoran Fakultas Ekonomi dan Bisnis Universitas Mataram yang terdapat di table 4.3 tersebut hanya terdiri dari 4 mata kuliah yaitu: Tiga Mata kuliah wajib dan inti masing-masing mempunyai 2 SKS adalah Mata Kuliah Pendidikan Kewarganegaraan, Pancasila dan Pendidikan Agama, mata kuliah pilihan dan bersifat institutional yaitu Bahasa Indonesia. Keempat mata kuliah tersebut secara nasional sudah ada ketentuan sendiri-sendiri, sehingga untuk melakukan perbaikan kurikulumnya tidak diserahkan kepada lembaga pendidikan yang ada tetapi justru lembaga pendidikan yang ada wajib mengikuti kurikulum nasional khusunya matakuliah pancasila dan kewarganegaraan.

\subsubsection{Kelompok Mata Kuliah Keilmuan dan Keahlian (MKK)}

Kelompok matakuliah keilmuan dan keahlian (MKK) adalah kelompok bahan kajian dan pelajaran yang ditujukan terutama untuk memberikan landasan penguasaan ilmu dan ketrampilan tertentu. Materi matakuliah MKK untuk Program D III Pariwisata Konsentrasi Hotel dan Restoran Fakultas Ekonomi dan Bisnis Universitas Mataram sebanyak lima mata kuliah.

Berdasarkan table 4.4. dapat dijelaskan bahwa lima MKK tersebut terdiri dari lima mata kuliah wajib dan inti dengan jumlah SKS 3 untuk mata kuliah pemasaran hotel dan 4 mata kuliah yang lainnya masing-masing mempunyai SKS 2 yaitu mata kuliah teknis supervise, manjemen hotel I, statistic pariwisata dan teknik penulisan laporan dan metodologi penelitian.

Tabel 4.4. Mata Kuliah Keilmuan dan Keahlian (MKK)

\begin{tabular}{|c|c|c|c|c|c|c|}
\hline \multirow[t]{2}{*}{ No } & \multirow{2}{*}{$\begin{array}{l}\text { Matakuliah Keilmuan dan Keahlian } \\
\text { (MKK) }\end{array}$} & \multicolumn{2}{|l|}{ SKS } & \multirow{2}{*}{$\begin{array}{l}\text { Kuri } \\
\text { kulum }\end{array}$} & \multirow{2}{*}{$\begin{array}{l}\text { Pilihan Resp/ } \\
28 \text { Resp }\end{array}$} & \multirow{2}{*}{$\begin{array}{l}\text { Tingkat } \\
\text { relevansi (\%) }\end{array}$} \\
\hline & & W & $P$ & & & \\
\hline 1 & Pemasaran Hotel & 3 & & Inti & 18 & 64.29 \\
\hline 2 & Statistik Pariwisata & 2 & & Inti & 17 & 60.71 \\
\hline 3 & Teknik Supervisi & 2 & & Inti & 16 & 57.14 \\
\hline 4 & Manajemen Hotel I & 2 & & Inti & 16 & 57.14 \\
\hline 5 & Tehnik Penulisan Lap Mtd Peneltian & 2 & & inti & 11 & 39.29 \\
\hline
\end{tabular}

Sumber: BukuPedoman Akademik D III Pariwisata FEB Unram dan data primer diolah.

Relevansi kurikulum Kelompok MKK dengan kebutuhan pasar tenaga kerja di sector pariwisata khususnya pada hotel dan restoran, berdasarkan hasil dari kuisioner yang diberikan kepada responden sebanyak 28 mahsiswa D III Pariwisata Konsentrasi Hotel dan Restoran Fakultas Ekonomi Unram yang 
melaksanakan Praktek Kerja Lapangan (PKL) pada hotel berbintang dan restoran yang ada di daerah Kota Mataram, Senggigi dan Tiga Gili yaitu Gili Air, Gili Meno dan Gili Trawangan selama tiga bulan dapat dijelaskan bahwa dari 28 responden mengatakan tingkat relevansi kurikulum kelompok MKK dengan pasar tenaga kerja secara berurutan dari yang tinggi ke yang rendah adalah mata kuliah pemasaran hotel sebanyak 18 responden (64,29\%), statistic pariwisata sebanyak 17 responden $(60,71 \%)$, teknik supervise dan manajemen hotel masing-masing sebanyak 16 responden (57,14\%) dan yang terendah tingkat relevansinya adalah mata kuliah tehnik penulisan laporan sebanyak 11 responden $(39,29 \%)$

\subsubsection{Mata Kuliah Keahlian Berkarya (MKB)}

Kelompok mata kuliah keahlian berkarya (MKB) adalah kelompok bahan kajian dan pelajaran yang bertujuan menghasilkan tenaga ahli dengan kekaryaan berdasarkan dasar ilmu dan ketrampilan yang dikuasai. Materi matakuliah MKB untuk Program D III Pariwisata Konsentrasi Hotel dan Restoran Fakultas Ekonomi dan Bisnis Universitas Mataram sebanyak 21 mata kuliah.

Tabel 4.5. Kelompok Mata kuliah Keahlian Berkarya (MKB)

\begin{tabular}{|c|c|c|c|c|c|c|}
\hline \multirow[t]{2}{*}{ No } & \multirow[t]{2}{*}{ Mata kuliah Keahlian Berkarya (MKB) } & \multicolumn{2}{|c|}{ SKS } & \multirow[t]{2}{*}{ Kurikulum } & \multirow{2}{*}{$\begin{array}{l}\text { Pilihan Resp/ } \\
28 \text { Resp }\end{array}$} & \multirow{2}{*}{$\begin{array}{l}\text { Tingkat } \\
\text { relevansi } \\
(\%)\end{array}$} \\
\hline & & W & $P$ & & & \\
\hline 1 & Tata Hidangan II & 2 & & Inti & 16 & 57.14 \\
\hline 2 & Pengolahan Makanan I & 2 & & Inti & 14 & 50.00 \\
\hline 3 & Pengolahan Makanan II & 2 & & Inti & 14 & 50.00 \\
\hline 4 & KaryaTulis & 4 & & Institusional & 14 & 50.00 \\
\hline 5 & Kantor Depan Hotel I & 2 & & Inti & 13 & 46.43 \\
\hline 6 & Kantor Depan Hotel II & 2 & & Inti & 13 & 46.43 \\
\hline 7 & Orientasi Kerja & 2 & & Institusional & 13 & 46.43 \\
\hline 8 & Tata Hidangan I & 2 & & Inti & 12 & 42.86 \\
\hline 9 & Akuntansi Hotel I & 2 & & Inti & 12 & 42.86 \\
\hline 10 & Praktik Kerja & 6 & & Institusional & 12 & 42.86 \\
\hline 11 & Praktikum Tata Graha \& Binatu & 4 & & Institusional & 11 & 39.29 \\
\hline 12 & Praktikum Pengolahan Makanan & 4 & & Institusional & 11 & 39.29 \\
\hline 13 & Hygiene dan Sanitasi Hotel & 2 & & Institusional & 11 & 39.29 \\
\hline 14 & Kuliah Lapangan & 2 & & Institusional & 11 & 39.29 \\
\hline 15 & Tata Graha \& Binatu I & 2 & & Inti & 10 & 38.46 \\
\hline 16 & Tata Graha \& Binatu II & 2 & & Inti & 10 & 35.71 \\
\hline 17 & Tata Graha \& Binatu III & 2 & & Inti & 10 & 35.71 \\
\hline 18 & Pengolahan Kue/Roti I & 2 & & Institusional & 10 & 35.71 \\
\hline 19 & Pengolahan Kue/Roti II & 2 & & Institusional & 10 & 35.71 \\
\hline 20 & Praktikum Pengolahan Kue/Roti & & 4 & Institusional & 10 & 35.71 \\
\hline 21 & Praktek Kantor Depan Hotel & 4 & & Institusional & 7 & 25.00 \\
\hline
\end{tabular}

Sumber: Buku Pedoman Akademik D III Pariwisata FEB Unram dan data primer diolah. 
Berdasarkan table 4.5 dapat dijelaskan bahwa dari 21 lima MKB tersebut terdiri dari 10 mata kuliah wajib dan inti, 10 mata kuliah wajib institusional dan 1 matakuliah pilihan institusional. Relevansi kurikulum Kelompok MKB dengan kebutuhan pasar tenaga kerja di sector pariwisata khususnya pada hotel dan restoran, berdasarkan hasil dari kuisioner yang diberikan kepada responden sebanyak 28 mahsiswa D III Pariwisata Konsentrasi Hotel dan Restoran Fakultas Ekonomi Unram yang melaksanakan Praktek Kerja Lapangan (PKL) pada hotel berbintang dan restoran yang ada di daerah Kota Mataram, Senggigi dan Tiga Gili yaitu Gili Air, Gili Meno dan Gili Trawangan selama tiga bulan dapat dijelaskan bahwa dari 28 responden mengatakan tingkat relevansi kurikulum kelompok MKB dengan pasar tenaga kerja yang tertinggi adalah mata kuliah Tata Hidang II sebanyak 16 responden $(57,14 \%)$, dan yang terendah tingkat relevansinya adalah mata kuliah Praktek Kantor Depan Hotel sebanyak 7 responden $(25,00 \%)$

\subsubsection{Mata Kuliah Perilaku Berkarya} (MPB)

Kelompok matakuliah perilaku berkarya (MPB) adalah kelompok bahan kajian dan pelajaran yang bertujuan untuk membentuk sikap dan perilaku yang diperlukan seseorang dalam berkarya menurut tingkat keahlian berdasarkan dasar ilmu dan keterampilan yang dikuasai. Materi matakuliah MKB untuk Program D III Pariwisata Konsentrasi Hotel dan Restoran Fakultas Ekonomi dan Bisnis Universitas Mataram sebanyak 21 mata kuliah.

Tabel 4.6. Kelompok Matakuliah Perilaku Berkarya (MPB)

\begin{tabular}{|c|c|c|c|c|c|c|}
\hline \multirow[t]{2}{*}{ No } & \multirow[b]{2}{*}{$\begin{array}{l}\text { Matakuliah Perilaku Berkarya } \\
\text { (MPB) }\end{array}$} & \multicolumn{2}{|c|}{ SKS } & \multirow[t]{2}{*}{ Kurikulum } & \multirow{2}{*}{$\begin{array}{l}\text { Pilihan } \\
\text { Resp/28 } \\
\text { Resp }\end{array}$} & \multirow[b]{2}{*}{$\begin{array}{l}\text { Tingkat } \\
\text { relevansi (\%) }\end{array}$} \\
\hline & & W & $P$ & & & \\
\hline 1 & Psikologi Pelayanan & 2 & & Inti & 17 & 60.71 \\
\hline 2 & Manajemen Konvensi & & 2 & Institusional & 15 & 53.57 \\
\hline 3 & Basic Profesional English & 4 & & Inti & 13 & 46.43 \\
\hline 4 & Kewirausahaan & & 2 & Institusional & 12 & 42.86 \\
\hline 5 & Pre Advance English & 4 & & Institusional & 12 & 42.86 \\
\hline 6 & Bahasa Jepang II & & 2 & Institusional & 12 & 42.86 \\
\hline 7 & Bahasa Jepang I & & 2 & Institusional & 11 & 39.29 \\
\hline 8 & Intermediate Prof. English & 4 & & Institusional & 11 & 39.29 \\
\hline 9 & Komputer & 2 & & Inti & 10 & 35.71 \\
\hline
\end{tabular}

Sumber: Buku Pedoman Akademik D III Pariwisata FEB Unram dan data primer diolah. 
Berdasarkan table 4.6 dapat dijelaskan bahwa dari 9 MPB tersebut terdiri dari 3 mata kuliah wajib dan inti yaitu: mata kulia Psikologi Pelayan dengan sks 2, Basic Profesional English dengan sks 4 dan Komputer sks 2. Kemudian mata kuliah wajib institusional ada 2 yaitu: mata kuliah Intermediate Profesional English dan Pre Advance Profesional English dengan sks masing-masing 4 . Sedangkan MPB yang lainnya kurikulumnya tergolong pada mata kuliah pilihan dan institusional dengan sks 2, untuk lebih jelasnya dapat dilihat pada table 4.6.

Relevansi kurikulum Kelompok MPB dengan kebutuhan pasar tenaga kerja di sector pariwisata khususnya pada hotel dan restoran, berdasarkan hasil dari kuisioner yang diberikan kepada responden sebanyak 28 mahsiswa D III Pariwisata Konsentrasi Hotel dan Restoran Fakultas Ekonomi Unram yang melaksanakan Praktek Kerja Lapangan (PKL) pada hotel berbintang dan restoran yang ada di daerah Kota Mataram,
Senggigi dan Tiga Gili yaitu Gili Air, Gili Meno dan Gili Trawangan selama tiga bulan dapat dijelaskan bahwa dari 28 responden mengatakan tingkat relevansi kurikulum kelompok MPB dengan pasar tenaga kerja tertinggi adalah kurikulum mata kuliah Psikologi Pelayanan sebanyak 17 responden (60,72\%) mengatakan relevan. Sedangkan kurikulum MPB yang mempunyai tingkat relevansi terendah adalah mata kuliah Komputer hanya sebanyak 10 responden $(35,71 \%)$.

\subsubsection{Mata Kuliah Berkehidupan} Bermasyarakat (MBB)

Kelompok matakuliah berkehidupan bermasyarakat (MBB) adalah kelompok bahan kajian dan pelajaran yang diperlukan seseorang untuk dapat memahami kaidah berkehidupan bermasyarakat sesuai dengan pilihan keahlian dalam berkarya. Materi matakuliah MKB untuk Program D III Pariwisata Konsentrasi Hotel dan Restoran Fakultas Ekonomi dan Bisnis Universitas Mataram sebanyak 8 mata kuliah.

Tabel 4.7. Kelompok Mata Kuliah Berkehidupan Bersama (MBB)

\begin{tabular}{|c|c|c|c|c|c|c|}
\hline \multirow{2}{*}{ No } & \multirow{2}{*}{$\begin{array}{l}\text { Mata Kuliah Berkehidupan Bersama } \\
\text { (MBB) }\end{array}$} & \multicolumn{2}{|c|}{ SKS } & \multirow{2}{*}{ Kurikulum } & \multirow{2}{*}{$\begin{array}{c}\text { Pilihan } \\
\text { Resp/ } 28 \\
\text { respn }\end{array}$} & \multirow{2}{*}{$\begin{array}{l}\text { Tingkat } \\
\text { relevansi }(\%)\end{array}$} \\
\hline & & W & $\mathrm{P}$ & & & \\
\hline 1 & Pengantar Ilmu Ekonomi & & 2 & Institusional & 15 & 53.57 \\
\hline 2 & Pengantar Akomodasi \& Restoran & 2 & & Institusional & 15 & 53.57 \\
\hline 3 & Pengantar Bisnis & & 2 & Institusional & 14 & 50.00 \\
\hline 4 & Dasar-dasar Manajemen & 2 & & Institusional & 13 & 46.43 \\
\hline
\end{tabular}




\begin{tabular}{|c|l|c|c|c|c|c|}
\hline 5 & Dasar-dasar Akuntansi & & 2 & Institusional & 13 & 46.43 \\
\hline 6 & Pengantar Pariwisata & 2 & & Inti & 13 & 46.43 \\
\hline 7 & Peraturan Pariwisata & & 2 & Institusional & 13 & 46.43 \\
\hline 8 & Public Relations & 2 & & Inti & 12 & 42.86 \\
\hline
\end{tabular}

Sumber: Buku Pedoman Akademik D III Pariwisata FEB Unram dan data $\mathrm{p}$ rimer diolah.

Berdasarkan table 4.7 dapat dijelaskan bahwa dari 8 MBB tersebut terdiri dari 2 mata kuliah wajib dan inti yaitu: mata kuliah Pengantar Pariwisata dan Public Relations dengan sks masingmasing 2, kemudian 2 mata kuliah wajib institusional yaitu mata kuliah Dasardasar manajemn dan Pengantar Akomodasi \& Restoran dengan sks masing-masing 2. Kemudian selebihnya ada 4 mata kuliah adalah pilihan institusional dengan sks masing-masing 2.

Relevansi kurikulum Kelompok MBB dengan kebutuhan pasar tenaga kerja di sector pariwisata khususnya pada hotel dan restoran, berdasarkan hasil dari kuisioner yang diberikan kepada responden sebanyak 28 mahsiswa D III Pariwisata Konsentrasi Hotel dan Restoran Fakultas Ekonomi Unram yang melaksanakan Praktek Kerja Lapangan (PKL) pada hotel berbintang dan restoran yang ada di daerah Kota Mataram, Senggigi dan Tiga Gili yaitu Gili Air, Gili Meno dan Gili Trawangan selama tiga bulan dapat dijelaskan bahwa dari 28 responden mengatakan tingkat relevansi kurikulum kelompok MBB dengan pasar tenaga kerja yang tertinggi adalah kurikulum mata kuliah Pengantar IImu Ekonomi sebanyak 15 responden (53,57\%) mengatakan relevan. Sedangkan kurikulum MBB yang mempunyai tingkat relevansi terendah adalah mata kuliah Public Rrlattions hanya sebanyak 12 responden (42,86\%).

\section{KESIMPULAN DAN SARAN}

\section{Kesimpulan}

Berdasarkan dari pembahasan pada bab IV relevansi kurikulum mata kuliah Program Studi D III Pariwisata Konsentrasi Hotel dan Restoran Fakultas Ekonomi dan Bisnis Universitas Mataram dapat disimpulkan sebagai berkut:

1. Pihak pengguna sebanyak 10 yang mengatakan bahwa kemampuan alumni secara umum masih dibawah standar rata-rata kompetensinya.

2. Pihak mahasiswa yang melakukan Praktek Kerja Lapangan (PKL) mengatakan relevansi kurikulum berdasarkan kelompok matakuliah terhadap pasar tenaga kerja yaitu: 
a. Kelompok Mata Kuliah Keilmuan dan Keahlian (MKK) mempunya relevansi yang cukup terhadap kebutuhan pasar tenaga kerja

b. Kelompok mata kuliah keahlian berkarya (MKB) mempunyai relevansi kurang terhadap kebutuhan pasar tenaga kerja

c. Kelompok matakuliah perilaku berkarya (MPB) mempunyai relevansi kurang terhadap kebutuhan pasar tenaga kerja

d. Kelompok matakuliah berkehidupan bermasyarakat (MBB) mempunyai relevansi kurang terhadap kebutuhan pasar tenaga kerja
Saran

1. Berkaitan dengan keahlian berdasarkan bidang ilmu atau kompetensi utama dilakukan rekontruksi kurikulum dan peningkatan kualitas proses belajar mengajar, terutama sarana dan prasarana laboratoriumnya dilengkaapi.

2. Berkaitan dengan keahlian berdasarkan integritas, komunikasi dan kerjasama tim mahasiswa perlu ditingkatkan soft skillnya dengan cara mahasiswa didorong untuk mengikuti kegiatan exktra kurikuler

\section{DAFTAR PUSTAKA}

Anonim. 2007. IImu Dan Aplikasi Pendidikan. ed181 pertama. Jakarta

Salsabila.Sari.2013. Relevansi Kurikulum Jurusan Kupkulum Dan Teknologi Pendidikan Dengan Dunia Kerja (Studi Kasus Guru Tik . Dinas Pendidikan, dan LembagaDiklat). Skripsi UNS Semarang

Schomburg. Harald (2003). Handbook for Graduate Tracer Study. Mocnchebergstrasse Kassel. Germany: Wissenschafthches Zentrum m: Bemfsund Hochschulforschung. Universitéit Kassel

Sugiyono. 2005.Statistik untuk Penelitian. Bandung: CV Alfabeta

Universitas Mataram. 2010. Kurikulum 2010. Mataram: UNRAM Press UNRAM. 